\title{
Prediction of Concrete Compressive Strength by Evolutionary Artificial Neural Networks
}

\author{
Mehdi Nikoo, ${ }^{1}$ Farshid Torabian Moghadam, ${ }^{2}$ and Lukasz Sadowski ${ }^{3}$ \\ ${ }^{1}$ Young Researchers and Elite Club, Ahvaz Branch, Islamic Azad University, Ahvaz, Iran \\ ${ }^{2}$ Young Researchers and Elite Club, khorasgan (Isfahan) Branch, Islamic Azad University, Isfahan, Iran \\ ${ }^{3}$ Faculty of Civil Engineering, Wrocław University of Technology, Wybrzeze Wyspiańskiego 27, 50-370 Wrocław, Poland
}

Correspondence should be addressed to Mehdi Nikoo; sazeh84@yahoo.com

Received 12 October 2014; Accepted 2 January 2015

Academic Editor: Chao Tao

Copyright (C) 2015 Mehdi Nikoo et al. This is an open access article distributed under the Creative Commons Attribution License, which permits unrestricted use, distribution, and reproduction in any medium, provided the original work is properly cited.

\begin{abstract}
Compressive strength of concrete has been predicted using evolutionary artificial neural networks (EANNs) as a combination of artificial neural network (ANN) and evolutionary search procedures, such as genetic algorithms (GA). In this paper for purpose of constructing models samples of cylindrical concrete parts with different characteristics have been used with 173 experimental data patterns. Water-cement ratio, maximum sand size, amount of gravel, cement, 3/4 sand, 3/8 sand, and coefficient of soft sand parameters were considered as inputs; and using the ANN models, the compressive strength of concrete is calculated. Moreover, using GA, the number of layers and nodes and weights are optimized in ANN models. In order to evaluate the accuracy of the model, the optimized ANN model is compared with the multiple linear regression (MLR) model. The results of simulation verify that the recommended ANN model enjoys more flexibility, capability, and accuracy in predicting the compressive strength of concrete.
\end{abstract}

\section{Introduction}

In the last decade, a lot of attention has been paid to the application of artificial neural networks (ANNs) in determining the compressive strength of concrete [1-9]. It is proper to note that there were mostly conventional applications of ANNs not disrupted in facing inaccurate data and information for this purpose. That is why many researchers used the combinatory models [10-12], such of ANN and fuzzy logic [13], which demonstrated strong potential for prediction of long-term effects of ground granulated blast furnace slag on compressive strength of concrete. In reducing the cost and saving time in the class of compressive strength's determination problems, cascade correlation type of ANN offered quick learning with slightly accurate performance for capturing the intrinsically nonlinear nature of patterns in the concrete properties [14]. Presenting substantial results in performance, combinatorial formations of ANN and meta-heuristic search algorithms have been increasing in utilization for encountering complex structural engineering problems. For instance, hybrid multilayer perceptron (HMLP) network with centre-unified particle swarm optimization was assigned for determination of the compressive strength of concrete related to the deep beams connected to the sheared walls and provided newsworthy results involved in significant efficiency [15]. In a similar area, compressive strength of self-compacting concrete, which encompassed polypropylene fiber and mineral additives, impressed by high temperature, was estimated by ANN [16]. According to [17] evolutionary artificial neural networks (EANNs) can be considered as a combination of artificial neural network (ANN) and evolutionary search procedures, such as genetic algorithms (GA). Basic principles of EANN were explained in [18]. The identification of defect in the structure and compressive strength of concrete is intrinsically a pattern-study issue, and for this purpose the EANNs have acted very powerfully $[19,20]$.

The main objective of this study is to determine the compressive strength of concrete using EANN as a replacement method for mathematical models and destructive tests so that more accurate results are obtained with the minimum cost. Similar data were previously analysed by using Self-Organization Feature Map (SOFM) systems and Kohonen training network and the $R^{2}$ coefficients in training, 
TABLE 1: Characteristics of cylindrical samples.

\begin{tabular}{lcccccc}
\hline Number & Parameters & Unit & Maximum & Minimum & Standard deviation & Mean \\
\hline 1 & Compressive strength of concrete & $\mathrm{kg} / \mathrm{cm}^{2}$ & 394.00 & 173.00 & 54.98 & 279.27 \\
2 & Water-cement ratio & - & 0.50 & 0.24 & 0.43 \\
3 & Maximum size of sand & $\mathrm{mm}$ & 50.00 & 5.12 & 2.19 & 14.25 \\
4 & Gravel & $\mathrm{kg}$ & 1050.00 & 559.00 & 95.71 & 779.13 \\
5 & Cement & $\mathrm{kg}$ & 549.00 & 243.00 & 385 \\
6 & Sand 3/8 & $\mathrm{kg}$ & 523.00 & 303.00 & 64.45 \\
7 & Sand 3/4 & $\mathrm{kg}$ & 693.00 & 365.00 & 90.06 \\
8 & Coefficient of soft sand & - & 9.20 & 2.40 & 563.31 \\
\hline
\end{tabular}

TABLE 2: Number of patterns used in ANN.

\begin{tabular}{lcc}
\hline Number & Number of patterns & Compressive strength of concrete \\
\hline 1 & 2 & $150-175$ \\
2 & 11 & $175-200$ \\
3 & 25 & $201-225$ \\
4 & 24 & $226-250$ \\
5 & 20 & $251-275$ \\
6 & 22 & $276-300$ \\
7 & 34 & $301-325$ \\
8 & 15 & $326-350$ \\
9 & 17 & $351-375$ \\
10 & 3 & $376-400$ \\
\hline \multicolumn{2}{l}{ Total of the number of patterns }
\end{tabular}

validation, and testing phases were equal to $0.880,0.993$, and 0.946 , respectively [21].

\section{Materials and Methods}

2.1. Database. Compressive strength of concrete $\left(f_{C}^{\prime}\right)$ is in fact the 28-day strength of cylindrical concrete sample. In this study, cylindrical samples with a diameter of $15 \mathrm{~cm}$ and a height of $30 \mathrm{~cm}$ are used. In addition, parameters such as the amount of $3 / 4$ sand, $3 / 8$ sand, cement, silt in kilograms, maximum sand size in millimeter, coefficient of fine sand, and water-cement ratio are used to determine the compressive strength of concrete. In the lab, using a hydraulic jack 25 blows are pounded on each sample of the concrete, and data related to the intended parameters towards determination of compressive strength are recorded. The characteristics of used data have been illustrated in Table 1 based on the data presented in the literature $[22,23]$.

Moreover, in Table 2, the number of patterns used in ANN has been shown based on compressive strength of concrete separately.

2.2. Research Methodology. The data were collected from the literature $[22,23]$ and have not been previously used in numerical modelling presented [21]. In the first step, several different mix designs are used to determine the compressive strength. Then Multi Layer (MLP), Feed Forward (FF), Radial Basis Function (RBF) and Time Lag Recarent Network

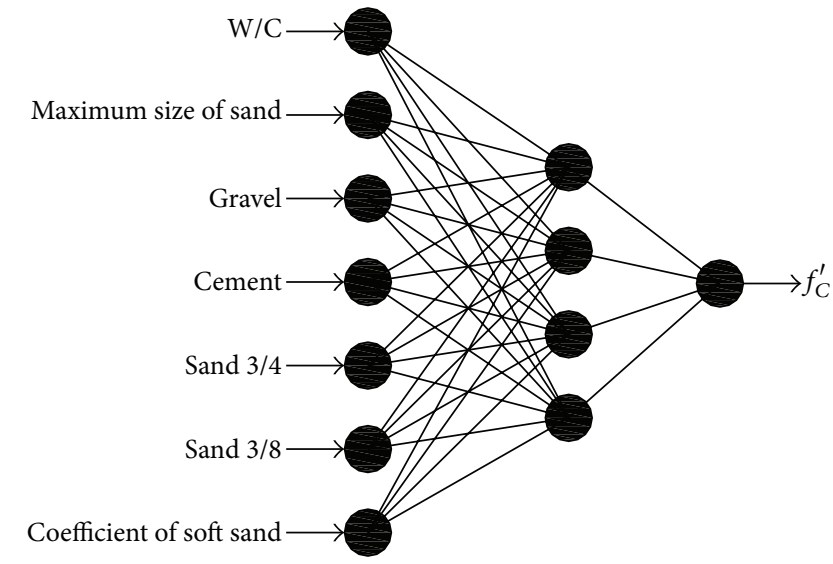

Figure 1: Structure of EANN.

(TLRN) were selected and the estimation of the compressive strength parameter have been carried out. Then the optimal geometric structure of the intended ANN along with optimal weights is tentatively determined by genetic algorithm (GA). In the next step, a multiple linear regression (MLR) model is employed in determining the compressive strength of concrete. Finally, the performance of the MLR model and the proposed EANN structure in predicting the compressive strength of concrete is studied and comparison between obtained models has been performed. In ANN models, the number of inputs is seven parameters and the number of outputs is one, which has been shown in Figure 1. Out of 173 data patterns, $80 \%$ (139 patterns) have been used for training, $10 \%$ (17 patterns) for cross validation, and 10\% (17 patterns) for network test. Various transfer functions consisting of LinearSigmoidAxon, BiasAxon, TanhAxon, LinearAxon, SigmoidAxon, LinearTanhAxon, and various training algorithms consisting of Momentum, Levenberg Marquat, Delta Bar Delta, Quickprop, and Step were considered to determine the best structure in the ANN [24]. In order to determine the number of nodes in the hidden layer, in addition to the software presupposition, the following experimental formula was used [25]:

$$
N_{H} \leq 2 N_{I}+1
$$

where $N_{H}$ is the maximum number of nodes in the hidden layer and $N_{I}$ is the number of inputs. With regard to the 
TABLE 3: Optimal structure of MLP, FF, RBF, and TLRN models obtained from GA.

\begin{tabular}{|c|c|c|c|c|c|c|c|c|c|}
\hline \multicolumn{2}{|c|}{ GA for all models } & \multirow{2}{*}{$\begin{array}{c}\begin{array}{c}\text { Learning } \\
\text { algorithm }\end{array} \\
\text { Momentum }\end{array}$} & \multirow{2}{*}{$\begin{array}{c}\text { Transfer function } \\
\text { TanhAxon }\end{array}$} & \multirow{2}{*}{$\begin{array}{c}\text { Number of } \\
\text { hidden } \\
\text { neuron }\end{array}$} & \multirow{2}{*}{$\begin{array}{c}\begin{array}{c}\text { Number of } \\
\text { hidden } \\
\text { layer }\end{array} \\
1\end{array}$} & \multirow[t]{2}{*}{$\begin{array}{c}\text { Number } \\
\text { of } \\
\text { output }\end{array}$} & \multirow[t]{2}{*}{$\begin{array}{l}\text { Number } \\
\text { of input }\end{array}$} & \multirow{2}{*}{$\begin{array}{c}\text { Model } \\
\text { MLP }\end{array}$} & \multirow{2}{*}{$\begin{array}{c}\text { Number } \\
1\end{array}$} \\
\hline Crossover & One point & & & & & & & & \\
\hline $\begin{array}{l}\text { Crossover } \\
\text { probability }\end{array}$ & 0.9 & Step & LinearAxon & 15 & 1 & 1 & 7 & $\mathrm{FF}$ & 2 \\
\hline $\begin{array}{l}\text { Mutation } \\
\text { probability }\end{array}$ & 0.01 & Delta Bar Delta & LinearSigmoidAxon & $4 \_4$ & 2 & & & $\mathrm{RBF}$ & 4 \\
\hline Generation & 100 & Momentum & TanhAxon & $5 \_10$ & 2 & & & TLRN & 3 \\
\hline
\end{tabular}

fact that the number of obtained effective inputs is equal to 7 , maximum number of nodes in the hidden layer is 15 $\left(N_{H} \leq 15\right)$. To determine the optimal structure of each ANN model together with the number of hidden layers, the number of nodes in the hidden layers, the network-learning algorithm and transfer function the in Neuro Solutions ver5.0 software has been used. Table 3 shows the optimal structure of each of the models and their various characteristics obtained from GA. In addition, Table 4 illustrates the results obtained from training, validation concurrent with training, and test of each model with the optimal structure obtained in Table 3. For the performance of the models, and to determine the best model, NMSE criterion and the coefficient of determination $(r)$ resulting from test of models are compared with one another. As seen in Table 4, MLP model has the highest correlation $(r)$ for the data regarding compressive strength of the concrete in all stages compared to the other three models.

In Figure 2 the comparison of observed compressive strength of concrete calculated by EANN models in the training stage has been presented. From Figure 2 it can be concluded that MLP and FF models in the training stage are closer to real data than other models. It can be also seen that TLRN model is the worst one during training stage. As presented in Figure 3 there is similar situation for testing and validation. The values predicted by MLP and FF seem to be the optimum. As it has been presented in Table 4, in MLP model, coefficients $R^{2}$ for compressive strength of concrete parameter in the training, validation, and test stages are equal to $0.910,0.935$, and 0.899 , respectively. In addition, the slope of the straight line for this parameter is $0.9061,0.9043$, and 0.9039 . These values are similar to the ones achieved in [21]. Therefore, MLP model has a higher correlation compared to the other three models. As a result, MLP model with a topology of (7-4-1) is the best EANN model with the structure presented in Figure 1.

2.3. Analysis of Sensitivity of Outputs of EANN Model in relation to Input Parameters. As you are training a network, you may want to know the effect that each of the network inputs is having on the network output. This provides feedback as to which input channels are the most significant. From there, you may decide to prune the input space by removing the insignificant channels. This will reduce the size of the network, which in turn reduces the complexity and the training times. Sensitivity analysis is a method for extracting the cause

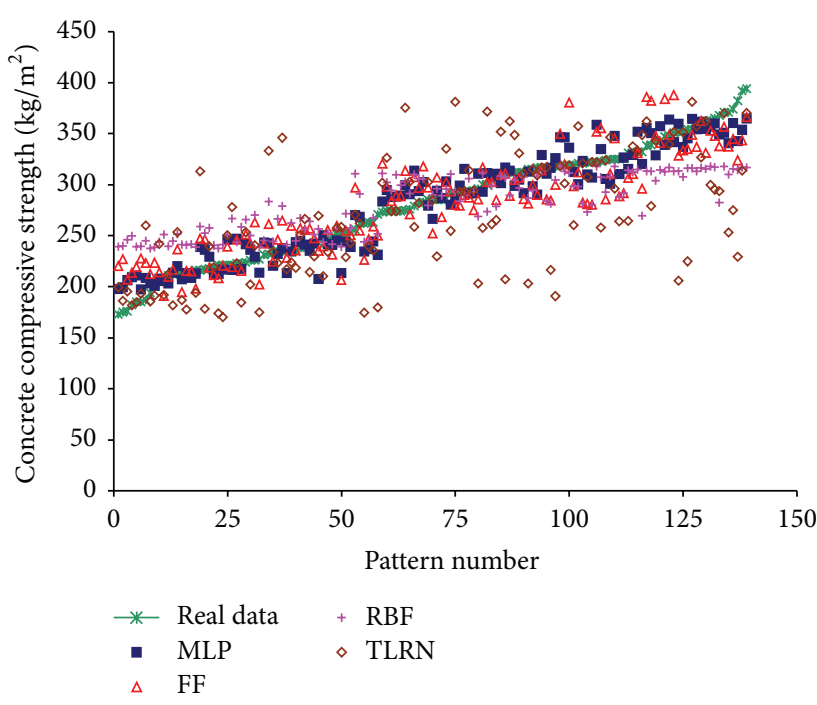

FIGURE 2: Comparison of observed compressive strength of concrete calculated by EANN models in the training stage.

and effect relationship between the inputs and outputs of the network. The network learning is disabled during this operation such that the network weights are not affected. The basic idea is that the inputs to the network are shifted slightly and the corresponding change in the output is reported as either a percentage or a raw difference. The activation control component generates the input data for the sensitivity analysis by temporarily increasing the input by a small value (dither). The corresponding change in output is the sensitivity data, which is reported by the ErrorCriteria component and displayed by an attached probe [24]. To determine the amount of effect of input parameters on the output parameter, sensitivity analysis technique is used. This technique is to determine to which input parameters the output parameter in the intended network is more sensitive so that which index is the most effective on the output of network is specified. The results obtained from the output sensitivity analysis of MLP model in relation to input parameters have been mentioned in Figure 4. With regard to Figure 4, water-cement ratio and 3/8 sand parameters have the most and the least effect on MLP model output, respectively.

2.4. Comparison between Selected EANN (MLP) Model and Multiple Linear Regression (MLR). The statistical model used 


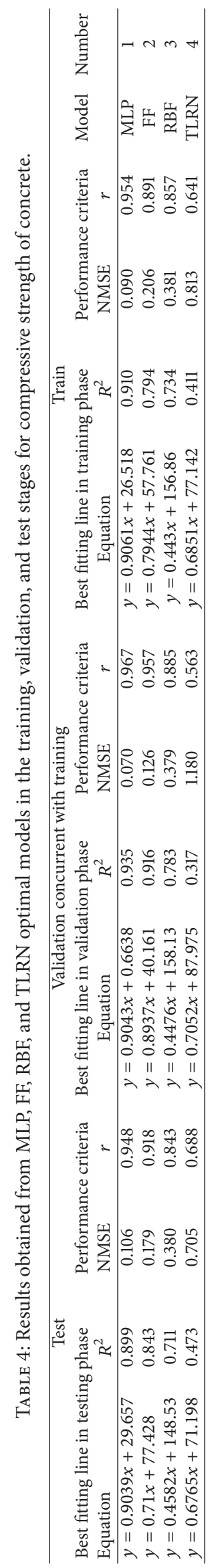


TABLE 5: Coefficients of MLR model.

\begin{tabular}{lccccc}
\hline$P$ & $T$ & SE coef. & Coef. & & Predictor \\
\hline-600 & 108 & -5.55 & 0 & Constant & Constant parameter \\
0.1685 & 0.1601 & 1.05 & 0.295 & $x_{1}$ & Water-cement ratio \\
0.1762 & 0.3456 & 0.51 & 0.611 & $x_{2}$ & Maximum size of sand \\
0.20611 & 0.05862 & 3.52 & 0.001 & $x_{3}$ & Gravel \\
1.01053 & 0.06292 & 16.06 & 0 & $x_{4}$ & Cement \\
0.4264 & 0.2541 & 1.68 & 0.096 & $x_{5}$ & Sand 3/8 \\
0.2452 & 0.1705 & 1.44 & 0.153 & $x_{6}$ & 5 \\
-0.529 & 1.756 & -0.3 & 0.764 & $x_{7}$ & Coefficient of soft sand \\
\hline
\end{tabular}

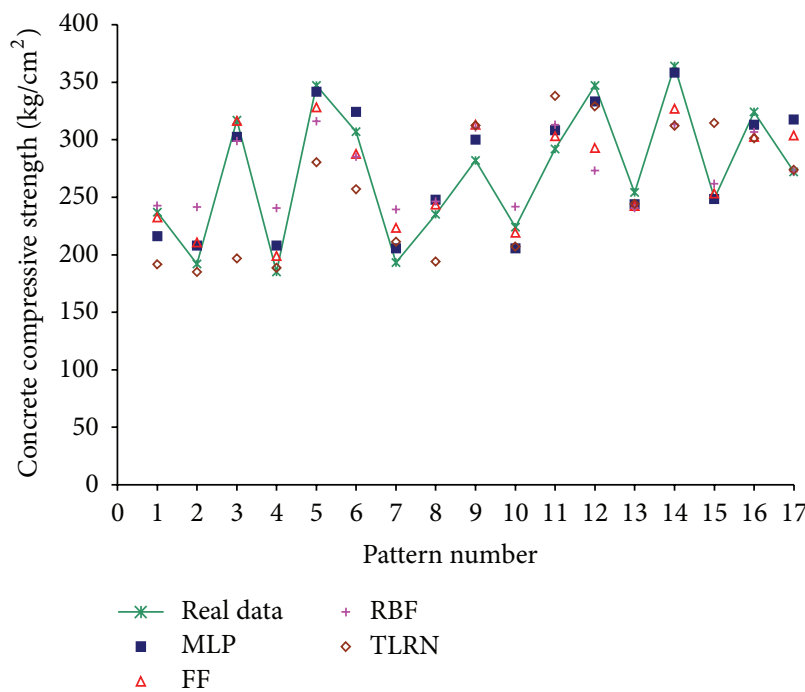

(a)

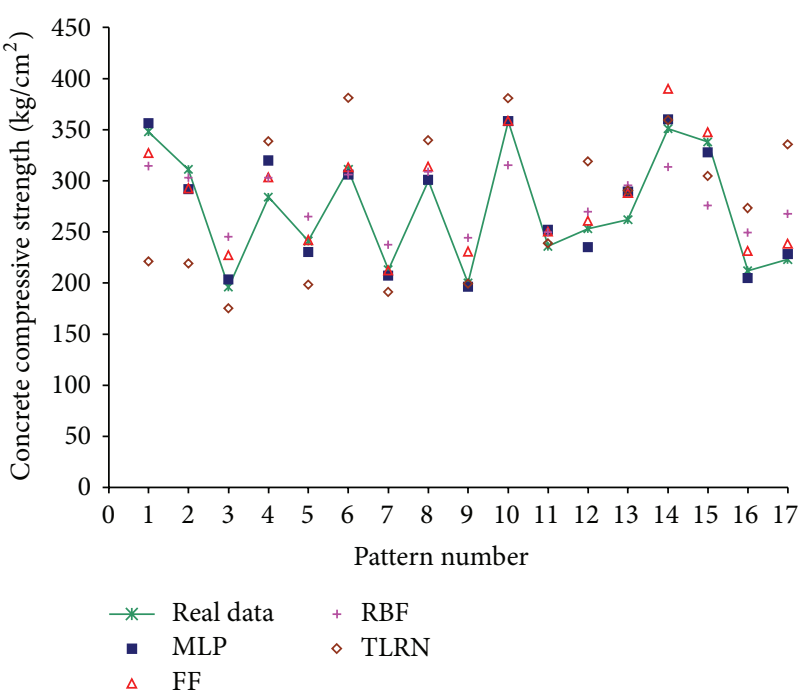

(b)

FIGURE 3: Comparison of observed compressive strength of concrete calculated by EANN models in testing (a) and validation (b) stage.

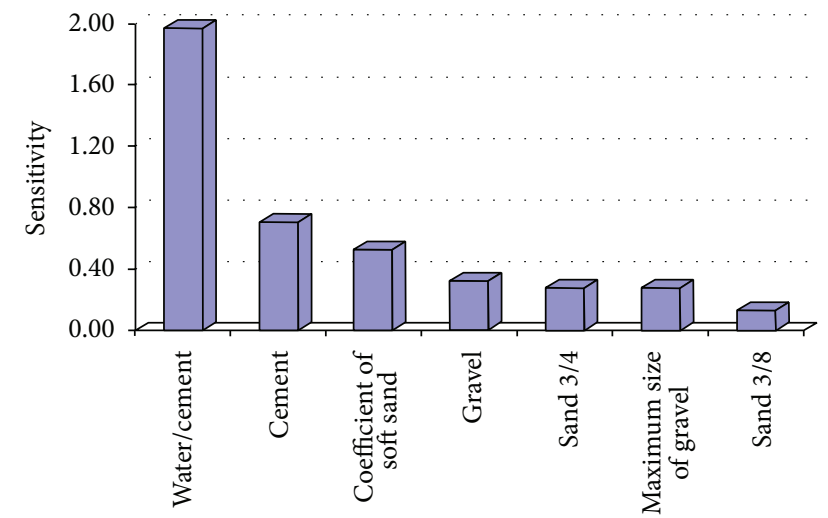

FIGURE 4: Sensitivity analysis of compressive strength of concrete for input parameters in MLP model.

in this research is the MLR, in which two or several independent variables have major effects on the dependent variable, and its equation is as follows:

$$
y=f\left(x_{1}, x_{2}, \ldots\right) \longrightarrow y=a_{0}+a_{1} x_{1}+a_{2} x_{2}+\cdots,
$$

where $y$ is the dependent variable, $x_{1}, x_{2}, \ldots$ are independent variables, and $a_{1}, a_{2}, a_{3}, \ldots$ are the equation coefficients of the regression type. In this study, for input and output variables various MLR models have been studied using MINITABver14.0 software. The most suitable coefficients for the MLR model are in Table 5. In this table, the numbers in Coef. column show the MLR model coefficients and the standard error of each of the estimates has been shown in SE coef. column. In order to obtain the confidence interval, 1.96 is to be multiplied by $95 \%$ of these numbers, and the result is algebraically added to the coefficients. In addition, the numbers in $T$ column are the division of Coef. by SE coef., which is used for the calculation of $P$ probability. In the assumption test this probability helps us accept or reject the answer. In principle, there is the probability of type 1 error. This type of error means, if less than $a=0.005$, that the relationship between these two parameters of independent and dependent is statistically very remarkable.

The best MLR model, which has the most correlation with compressive strength of concrete, has been mentioned in

$$
\begin{aligned}
Y= & -600+0.168 x_{1}+0.176 x_{2}+0.206 x_{3}+1.01 x_{4} \\
& +0.426 x_{5}+0.245 x_{6}-0.53 x_{7} .
\end{aligned}
$$

$Y$ is the compressive strength of concrete, with regard to (3), and using data obtained from training, the amount of 


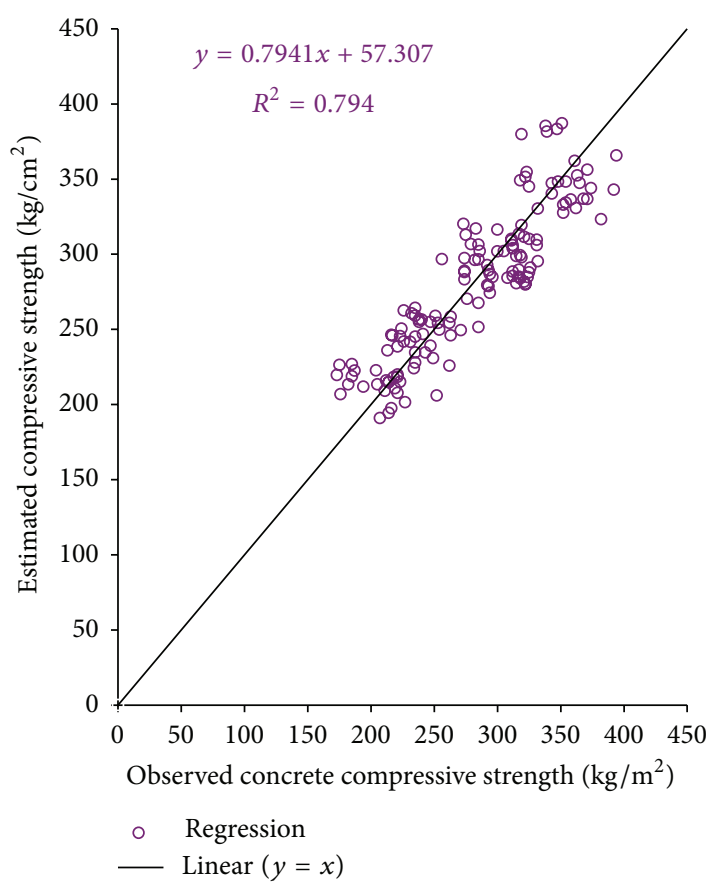

FIGURE 5: Comparison of observed compressive strength of concrete that calculated one with regression model.

compressive strength of concrete can be calculated. In the MLR model, $R^{2}$ coefficient for $y$ dependent parameter equals 0.794. In addition, the slope of the straight line for this parameter equals 0.794 , which is suitable for this model. The amount of $R^{2}$ and the slope of the straight line for (3) have been illustrated in Figure 5.

In order to validate the performance of MLP optimal model in the prediction of compressive strength of concrete, the results obtained from it are compared with those obtained from MLR model. For this purpose, and in order to make predictions, ten laboratory samples have been used with the two models. Among the most important advantages of these samples is that none of them has been used in the training, validation, and test stages. Figure 6 illustrates a comparison between the amounts of observed and calculated compressive strength of concrete as obtained from the two models. Moreover, the prediction of compressive strength of concrete with EANN (MLP) and MLR models has been presented in Figure 7.

With regard to the equations of regression lines on the amounts of calculated and observed compressive strength of concrete in each model in Figure 6 and the determination coefficient, it can be realized that the EANN (MLP) model determines the compressive strength of concrete more precisely than the MLR model does. In addition, with regard to the prediction of compressive strength of concrete by the two models in Figure 7, it can be realized that EANN (MLP) model has higher flexibility and accuracy compared to the multiple linear regression model. These results originate from the adaptable and learning capabilities of ANN in the nonlinear dynamic estimation of problems and complicated models.

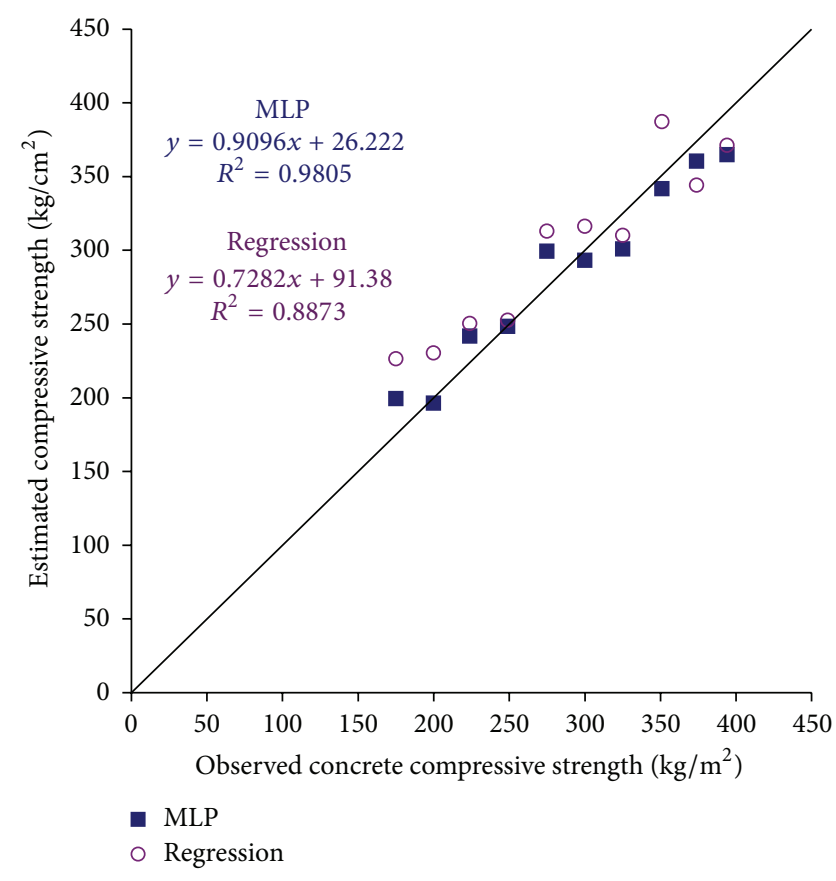

FIGURE 6: Comparison of observed compressive strength of concrete and estimated compressive strength by EANN (MLP) and MLR regression model.

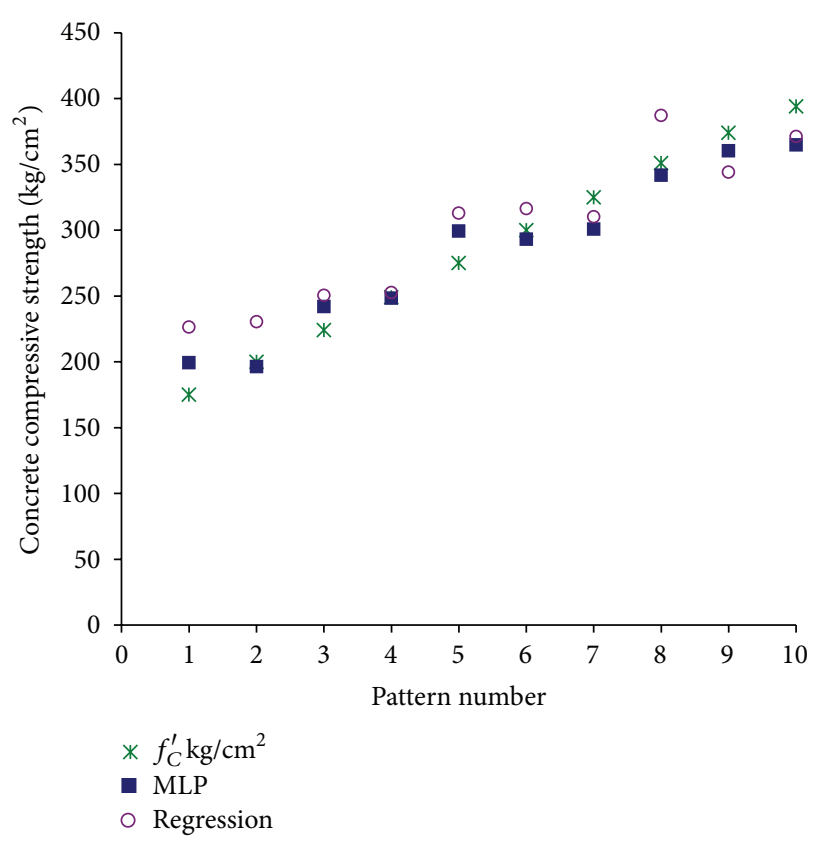

FIGURE 7: Prediction of compressive strength of concrete with EANN (MLP) and MLR regression model.

\section{Conclusion}

In this study, in order to economize on the time and cost that laboratory methods have in determining the compressive strength of concrete, the model suggested by the ANN, which has special capability in nonlinear mapping, was used. 
Various geometric structures along with various learning algorithms were suggested for network architecture.

In order to obtain the required accuracy towards determining compressive strength, the optimal evolutionary artificial neural networks (EANNs) structures consisting of optimal geometry in the number of hidden neurons and layers along with optimal learning algorithm relying on the high power of GA were presented. In addition, the linear regression statistical model was used to estimate the compressive strength and to compare its results for the validation of suggested EANN performance based on GA. The comparison of the results, whether qualitative or quantitative, was made between the statistical model and the optimized EANN.

On the basis of performance criteria like normalized mean square error, coefficient of determination, and correlation coefficient, it clearly confirms the superiority of EANN from the point of accuracy, correctness, and eye-catching flexibility of this structure in facing multidimensional, nonlinear, complicated problems like estimation of compressive strength parameter. These obtained values of correlation coefficient $R^{2}$ for compressive strength of concrete parameter in the training, test, and validation stages were achieved equal to $0.910,0.935$, and 0.899 , respectively, and are similar to the ones achieved in [21]. In addition, the slope of the straight line for this parameter is 0.9061, 0.9043, and 0.9039. Based on these results, which are proof of reliability of suggested strategy in this study, the generalization property of EANN has also been used in predicting the amounts of compressive strength based on unused collected data.

\section{Conflict of Interests}

The authors declare that there is no conflict of interests regarding the publication of this paper.

\section{References}

[1] S.-C. Lee, "Prediction of concrete strength using artificial neural networks," Engineering Structures, vol. 25, no. 7, pp. 849-857, 2003.

[2] U. Atici, "Prediction of the strength of mineral admixture concrete using multivariable regression analysis and an artificial neural network," Expert Systems with Applications, vol. 38, no. 8, pp. 9609-9618, 2011.

[3] I. B. Topçu and M. Saridemir, "Prediction of compressive strength of concrete containing fly ash using artificial neural networks and fuzzy logic," Computational Materials Science, vol. 41, no. 3, pp. 305-311, 2008.

[4] T.-K. Lin, C.-C. J. Lin, and K.-C. Chang, "Neural network based methodology for estimating bridge damage after major earthquakes," Journal of the Chinese Institute of Engineers, vol. 25, no. 5, pp. 415-424, 2002.

[5] A. Öztaş, M. Pala, E. Özbay, E. Kanca, N. Çaglar, and M. A. Bhatti, "Predicting the compressive strength and slump of high strength concrete using neural network," Construction and Building Materials, vol. 20, no. 9, pp. 769-775, 2006.

[6] M. A. Kewalramani and R. Gupta, "Concrete compressive strength prediction using ultrasonic pulse velocity through artificial neural networks," Automation in Construction, vol. 15, no. 3, pp. 374-379, 2006.
[7] A. Alexandridis, D. Triantis, I. Stavrakas, and C. Stergiopoulos, "A neural network approach for compressive strength prediction in cement-based materials through the study of pressurestimulated electrical signals," Construction and Building Materials, vol. 30, pp. 294-300, 2012.

[8] J. Hola and K. Schabowicz, "Methodology of neural identification of strength of concrete," ACI Materials Journal, vol. 102, no. 6, pp. 459-464, 2005.

[9] G. Trtnik, F. Kavčič, and G. Turk, "Prediction of concrete strength using ultrasonic pulse velocity and artificial neural networks," Ultrasonics, vol. 49, no. 1, pp. 53-60, 2009.

[10] J.-S. Chou, C.-K. Chiu, M. Farfoura, and I. Al-Taharwa, "Optimizing the prediction accuracy of concrete compressive strength based on a comparison of data-mining techniques," Journal of Computing in Civil Engineering, vol. 25, no. 3, pp. 242253, 2011.

[11] Ł. Sadowski, M. Nikoo, and M. Nikoo, "Principal component analysis combined with a self organization feature map to determine the pull-off adhesion between concrete layers," Construction and Building Materials, vol. 78, pp. 386-396, 2015.

[12] L. Sadowski and M. Nikoo, "Corrosion current density prediction in reinforced concrete by imperialist competitive algorithm," Neural Computing and Applications, vol. 25, no. 7-8, pp. 1627-1638, 2014.

[13] M. Saridemir, I. B. Topçu, F. Özcan, and M. H. Severcan, "Prediction of long-term effects of GGBFS on compressive strength of concrete by artificial neural networks and fuzzy logic," Construction and Building Materials, vol. 23, no. 3, pp. 1279-1286, 2009.

[14] M. M. Alshihri, A. M. Azmy, and M. S. El-Bisy, "Neural networks for predicting compressive strength of structural light weight concrete," Construction and Building Materials, vol. 23, no. 6, pp. 2214-2219, 2009.

[15] H.-C. Tsai, "Predicting strengths of concrete-type specimens using hybrid multilayer perceptrons with center-unified particle swarm optimization," Expert Systems with Applications, vol. 37, no. 2, pp. 1104-1112, 2010.

[16] M. Uysal and H. Tanyildizi, "Estimation of compressive strength of self compacting concrete containing polypropylene fiber and mineral additives exposed to high temperature using artificial neural network," Construction and Building Materials, vol. 27, no. 1, pp. 404-414, 2012.

[17] X. Yao, "Evolutionary artificial neural networks," in Encyclopedia of Computer Science and Technology, vol. 33, pp. 137-170, 1995.

[18] S. Ding, H. Li, C. Su, J. Yu, and F. Jin, "Evolutionary artificial neural networks: a review," Artificial Intelligence Review, vol. 39, no. 3, pp. 251-260, 2013.

[19] R. Madandoust, R. Ghavidel, and N. Nariman-Zadeh, "Evolutionary design of generalized GMDH-type neural network for prediction of concrete compressive strength using UPV," Computational Materials Science, vol. 49, no. 3, pp. 556-567, 2010.

[20] M. Nikoo, P. Zarfam, and M. Nikoo, "Determining displacement in concrete reinforcement building with using evolutionary artificial neural networks," World Applied Sciences Journal, vol. 16, no. 12, pp. 1699-1708, 2012.

[21] M. Nikoo, P. Zarfam, and H. Sayahpour, "Determination of compressive strength of concrete using Self Organization Feature Map (SOFM)," Engineering with Computers, vol. 31, no. 1, pp. 113-121, 2015. 
[22] A. Oner and S. Akyuz, "An experimental study on optimum usage of GGBS for the compressive strength of concrete," Cement and Concrete Composites, vol. 29, no. 6, pp. 505-514, 2007.

[23] K. M. Lee, H. K. Lee, S. H. Lee, and G. Y. Kim, "Autogenous shrinkage of concrete containing granulated blast-furnace slag," Cement and Concrete Research, vol. 36, no. 7, pp. 1279-1285, 2006.

[24] NeuroSolutions, Getting Started Manual Version 4, Neural Network Based System Identification Toolbox, NeuroSolutions, 2005.

[25] G. J. Bowden, G. C. Dandy, and H. R. Maier, "Input determination for neural network models in water resources applications. Part 1-background and methodology," Journal of Hydrology, vol. 301, no. 1-4, pp. 75-92, 2005. 

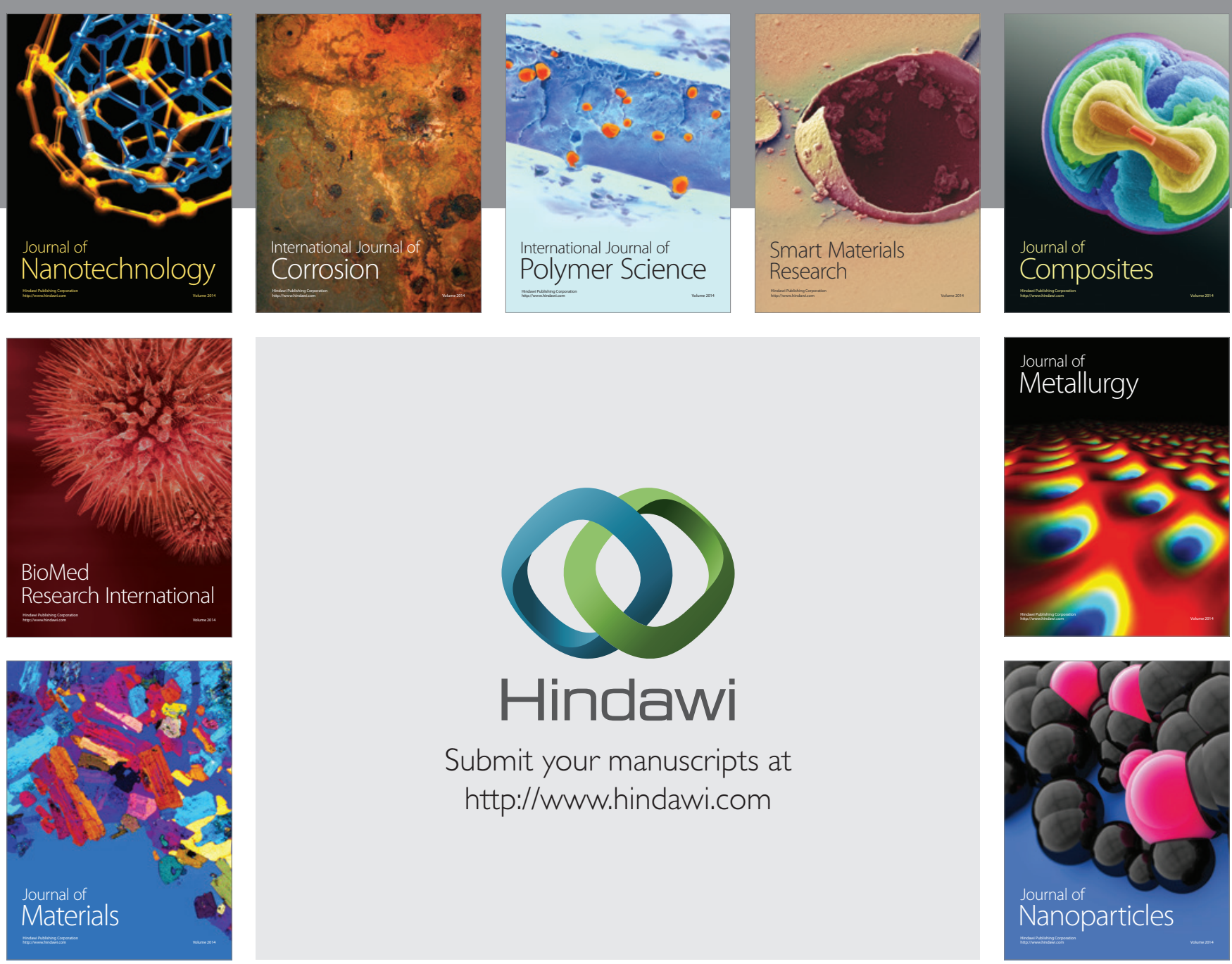

Submit your manuscripts at http://www.hindawi.com
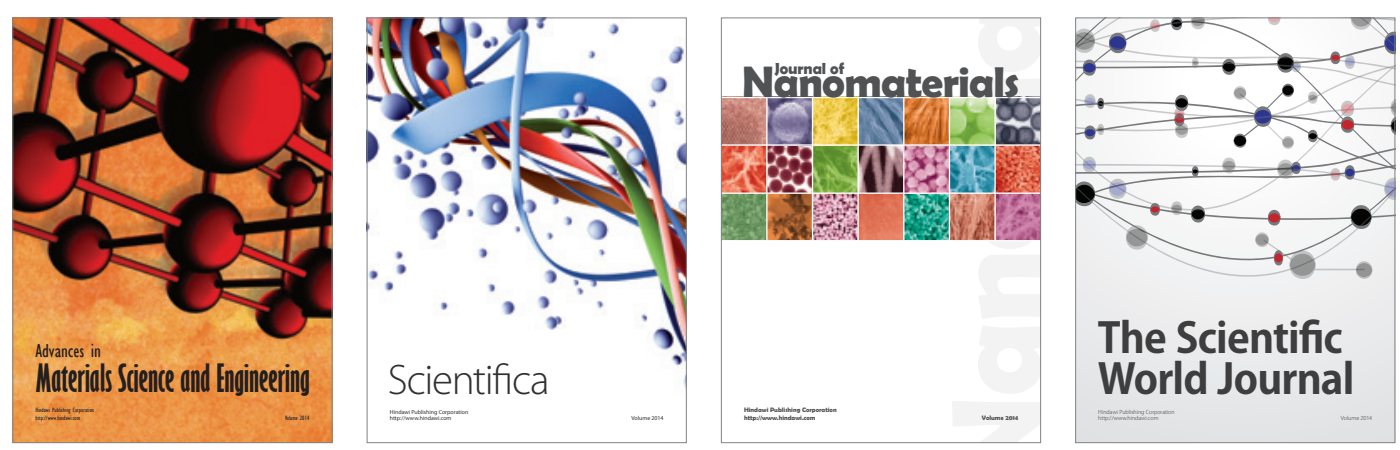

\section{The Scientific World Journal}
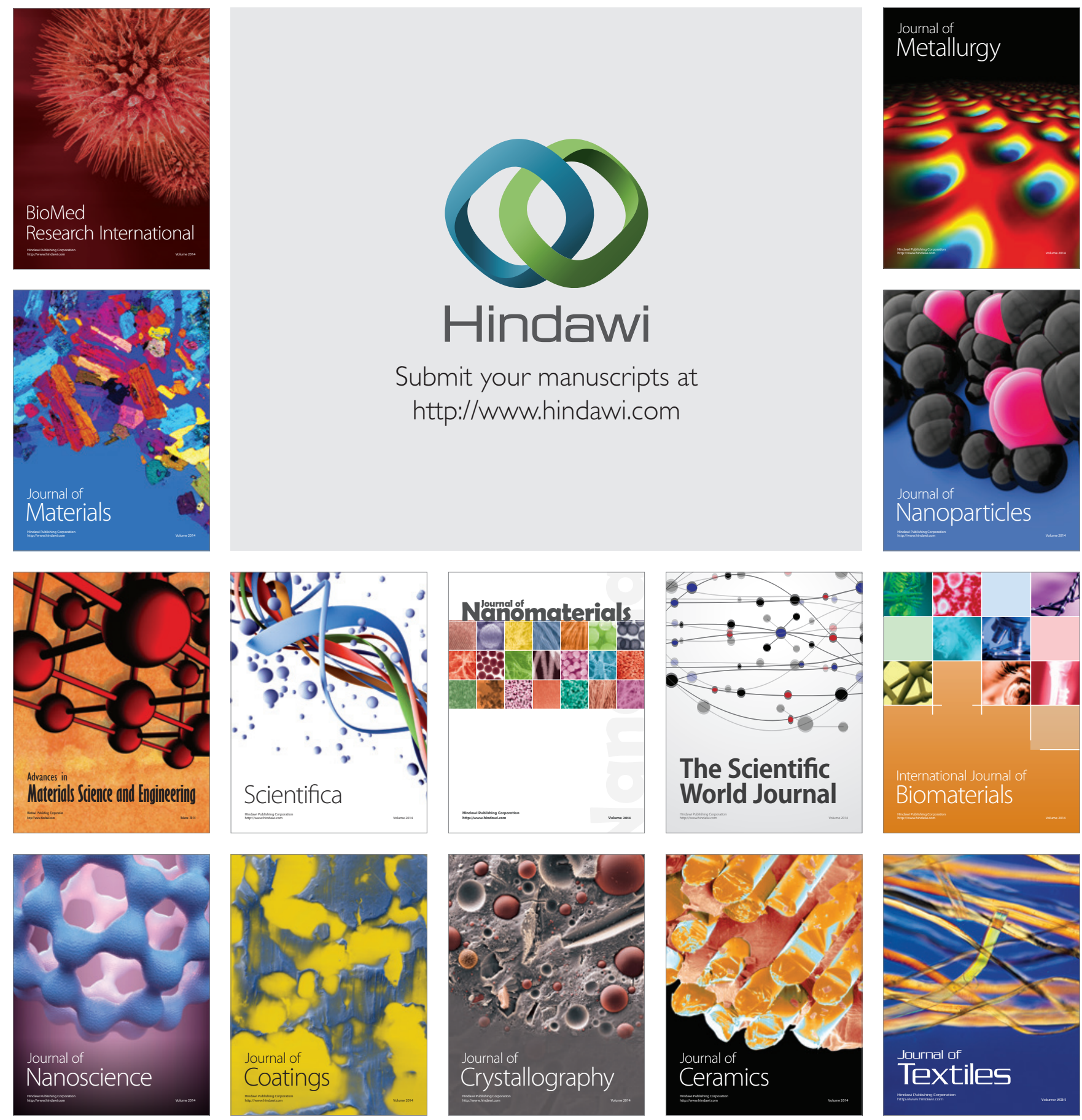